\title{
Human Genome as an Object of Interdisciplinary Socio- Humanitarian Research and a System of Appropriate Methodological Means
}

\author{
Fyodor $V$. Fetyukov* \\ Ural State Law University, 21, Komsomolskaya Str., 620137, Yekaterinburg, Russia
}

\begin{abstract}
The research is based on a comprehensive analysis of scientific articles devoted to the problems of obtaining, storing and using genomic information about a person. As a result of the analysis, the author put forward a hypothesis about the interdisciplinary interaction of social sciences and humanities in the process of research, the object of which is the human genome. The study tests the proposed hypothesis on the basis of the disclosure of its subject - the human genome as an object of interdisciplinary social and humanitarian research and the system of methodological means corresponding to them. During the research, the author relied on the general philosophical means of the methodology of science (categories of materialistic dialectics, foundations, conditions and principles of scientific knowledge), the systemstructural method and general logical methods (analogy, synthesis, analysis) used in socio-humanitarian studies. As a result of the study, it was concluded that the special significance of the consequences of the study and use of human genome for society and each individual personally determines the a priori social and humanitarian interdisciplinary connections, due to which human genome becomes the object of interdisciplinary social and humanitarian research. The analysis of these studies allowed revealing their subject orientation towards the social regulation of genomic research, the legal protection of genomic information and the focus on standardization (and in this sense, foreseeability) of research on human genome and the use of their results. At the same time, the use of methodological means of three levels is traced: philosophical and methodological analysis, general scientific methodological principles and a special scientific methodological approach.
\end{abstract}

\section{Introduction. Interdisciplinary aspect in modern science}

One of the main characteristics of modern post-nonclassical science is the change in the nature of the object of research and intensification of the role of interdisciplinary integrated approaches in its study. "Human-sized" systems are becoming the object of modern science: medico-biological, environmental and biotechnological objects (primarily genetic engineering), "man-machine" systems. The change in the nature of the object of research leads to a change in approaches and research methods.

The intention to build a general scientific picture of the world in modern science is set by synergetic methodological guidelines for the study of selfdeveloping integral objects, explicated in complex, nonlinear, unstable and nonequilibrium systems. Since the $20^{\text {th }}$ century, it has been widely known that the exchange of paradigmatic attitudes has intensified both between the natural sciences and between natural sciences and social and humanitarian sciences. Under these conditions, the traditional lines between the sciences of the spirit and the life sciences (V. Dilthey), natural and historical sciences/ cultural sciences (V. Windelband, G. Rickert) are blurred and interdisciplinarity takes on the character of a methodological norm.

As a rule, the interdisciplinary situation occurs from the transfer of a method from one area of scientific knowledge to another. In this case, the method is transferred from the outside to a specific scientific field of knowledge only partially. It means that certain elements and foundations of the method, including those contained in general scientific and universal methods, which are integrated into a qualitatively new mental formation, are subject to transfer.

The example of such an interdisciplinary situation is the presentation by G. Mendel of the idea of discrete heredity (the factor of heredity) due to the simultaneous use of the achievements of biology and the probabilisticstatistical method of mathematics. As it can be seen, the use of methods that are unusual for a particular science can cause a synergistic effect and lead to the emergence of new scientific knowledge. 
The interdisciplinary situation can also occur when new ideas and concepts, or even the subject of research itself, penetrate from another area into a research area based on an important scientific method. In science, the transfer of methods, principles, ontological concepts, methods of systematic design of existing knowledge from one group of sciences to another is called the methodological interaction of sciences or "paradigmatic vaccination".

Paradigmatic vaccinations are often attributed to social science and humanities from the subject areas of natural science, in particular, from biology (the concept of society as a single organism by A. Comte), cybernetics, systems theory, information theory (achievements of modern linguistics). Therefore, the interdisciplinary approach is recognized as an immanent property of the sociological and humanitarian paradigm of methodological thinking.

Synthetic areas of knowledge are sometimes the result of such paradigmatic vaccination. For example, psychogenetics studies the role of genotype in the determination of individual development, in particular, deviant behavior, which is important for penitentiary practice. Behavioral genetics studies the way how genetic differences between people affect differences in their psychology and behavior [1]. Numerous studies convincingly prove the influence of a genetic factor on a predisposition to suicide [2], alcoholism [3], pedophilia [4], drug addiction [5].

The concept of this study is based on the hypothesis of interdisciplinary interaction of social sciences and humanities in the process of the study of human genome. Its subject is formed by human genome as an object of interdisciplinary social and humanitarian research and the system of methodological tools used in this process.

The author proceeds from the priority of the problem over the method, since the need to use a certain method is caused by objects and phenomena of objective reality. Therefore, first of all it is necessary to briefly characterize the peculiarity of human genome as an object of research.

\section{Human genome as an object in socio- humanitarian research}

The object of research is always a special selected fragment of reality, the boundaries of which are outlined by science. It is obvious that a human genome is a special biological object. Despite the biological nature of this object, it a priori contains socio-humanitarian intersubject connections determined by the consequences of the study of a human genome for society and each person individually. Probably, this explains the genuine interest of the representatives of social sciences and humanities in the study of such a complex and unusual object for socio-humanitarian studies.

The analysis of scientific sources on this topic showed the stability of the statement about the uncertainty of ethical, legal and social consequences of the use of technologies for editing the germline genome, obtaining and using the results of human genome sequencing. As a result of the intensive development of technologies for human genome editing, which is significantly ahead of the process of critical understanding of their application (including legal regulation), there are tensions in society raising question concerning the basic valueson which moral and legal norms are based [6].

In public consciousness, the reflection on the processes of accumulation and practical application of knowledge about human genome is determined by evaluative categories of benefit and harm or their ratio. When there is no reliable and complete information about the biomedical and social consequences of the study of human genome, an adequate assessment by society is extremely difficult. The choice of the optimal legal regime for handling this object is even more difficult. The subjects of interdisciplinary research that solve the problems of standardization (and foreseeability in this sense) of the study of human genome and the use of the corresponding results can be conditionally divided into two groups. The first group is the social regulation of genomic research. The second group is the legal protection of genomic information aimed to eliminate the risks of unlawful use of the results of genomic research.

The peculiarity of social regulation of genomic research is the absence of a clear division on the subject of regulation in this area of social relations between different social norms (morality, legal norms, religious norms and customs). Dialectical links between social regulators are explained by the unity of the values they pursue (life, health, honor and dignity of a person, his self-identity, interest, etc.). For example, ethical issues arise during the establishment of a regime of access for law enforcement agencies to DNA databases and control over the information contained in them by state participants in genomic relations [7], as well as during the establishment of a legal regime for research in the field of human embryo genome editing [8].

Many researchers note the need to apply legal science and legislative practice to regulate the problems of genetic medicine, biology and human genetics in accordance with the achieved results and open perspectives. They rely on these results and anticipate social and, therefore, legal consequences of future perspective [2].

Legal regulation of public relations in the field of genomic research and the use of the resulting genetic information can and should claim a leading role in the system of social regulation. Firstly, legal norms are the most effective tool to influence behavior of people due to general obligation, formal certainty and normativity. Secondly, legal norms are often based on ideas about the proper behavior of people formed in other social norms. One of the studies showed that national legislation should reflect the need to develop a unified methodology for interdisciplinary studies of human genome and determine the ways and prospects for its use [9]. However, this would mean an attempt by the state to get into the research process itself, which is detrimental to the development of any scientific knowledge. Therefore, one should join the call of researchers to be careful about 
excessive imposition of moratoriums and prohibitions that negatively affect basic research and the recommendation to look for flexible rules developed as a result of stakeholder participation in lawmaking [10].

There is a fairly widespread position among researchers on the need to intensify prohibitions and restrictions during the work with human genome. For example, in order to protect the environment and ensure the ecological safety of humans and rational use of natural resources, the system of legal prohibitions and restrictions in any genomic research was considered reasonable [11] and the existing legal remedies and mechanisms were proposed to be used in relation to the prohibition of human embryo genome editing [12 ].

The author of this study is deeply convinced that the use of bans in the field of human genome research is not always justified. First, such measures will hold back the scientific progress in genetics, which millions of people in the world already need. Secondly, as practice shows, even the most severe prohibitions and criminal liability do not exclude the obsession of scientists with new discoveries. The existing legal restrictions are insufficient for the proper regulation of public relations in the field of genomic research and the use of genomic information.

For example, a particular study described legislative loopholes to circumvent international restrictions on germline genome editing. It is noted that these restrictions do not fully consider the comprehensive consequences of new technologies for society and humanity [13]. Thirdly, the prohibitions only temporarily postpone the objective necessity of normative legal regulation of social relations emerging in the field of research and use of human genome.

The use by the legislators of an imperative normative structure as a model of legal regulation, combining a prohibition established by a special law and legal responsibility, is justified only in cases where experiments with human genome are associated with a risk to human life or can lead to the loss of the uniqueness of a person as a biological species (for example, reproductive cloning, germline editing).

In all other cases, the legislators should provide researchers of human genome with the opportunity to work for the benefit of all mankind under the control of the state establishing exceptions to the general prohibition. For this, it is necessary to form an appropriate state licensing and control system. Mandatory elements of this system should be government agencies and institutions that provide control (federal service) and the provision of services (federal agency, government agencies) in the field of research and use of human genome.

More and more countries are moving towards the adoption of regulatory legal acts in the field of experiments with human genome. Lawyers are convinced that the legal regulation of genomic research will help formulate a pragmatic attitude to the problem and find a balance between the risk and benefits of human knowledge [14]. Tax incentives, credit incentives, public-private partnerships, etc. have been proposed as legal means of the stimulation of legal support for genomic research [11].

Along with the continuing leading role of law in the regulation of social relations in this area, their participants should be guided by other social norms. In this regard, it is necessary to pay attention to the model of modular regulation of public relations presented in the scientific literature, which overcomes the shortcomings of legal regulation and ensures public order in the field of genomic research.

The essence of this model is in the choice of the most effective social norm from the entire system of social norms (moral, legal, corporate, religious norms) at the discretion of the subject. At the same time, modular regulation has limited application and does not replace legal regulation [15].

The second group of studies is devoted to the protection of genomic information in connection with the multiple risks of illegal use of the results of genomic research. The group of these studies reveals the implementation of the protective function of law in relation to genomic legal relations, while in the first group of studies we consider the implementation of the regulatory-static and regulatory-dynamic functions of law.

The need to protect human rights in the field of genomic information is caused by a wide range of risks. Most of them are associated with the threat of leak of confidential genomic information, which can occur unintentionally or as a result of its deliberate transfer to the platforms of genetic services [16] or hacking of biobanks of genomic information [17]. Genomic information can be used by intruders as a basis for genetic discrimination [18].

The scientific literature also discusses the risks of liability of health care providers and testing laboratories [19]. In the context of the increased public danger of violation of human rights and freedoms in this area, scientists often use the mechanism of criminal law protection of such relations [20].

The protection of human rights in the field of genomic information also performs a security function in civil circulation. For example, an agreement with a medical organization on sequestration contains a condition on the confidentiality of information. It is obvious that the involvement of genome in civilian circulation is not a distant prospect. The only obstacle to this is the uncertainty of the legal nature of genome.

This circumstance causes the complexity of the legal perception of human genome in legal doctrine and law enforcement practice. For example, in private law, compensation for damage is one of the ways to protect violated rights. Therefore, the literature rightly showed the need to establish clear legal principles for compensation for damage caused as a result of gene editing in human embryos and reproductive cells [21]. 


\section{Methodological tools used in interdisciplinary social and humanitarian studies of human genome}

It is well known that three levels of methodological knowledge are used in the determination of the object of research: philosophical and methodological analysis, general scientific methodological principles and a special scientific methodological approach.

As a rule, using philosophical and methodological analysis the object is reduced as a fragment of reality to the object of a specific study. Philosophical and methodological analysis allows outlining directly visible reality within the boundaries set by the content of fundamental scientific concepts and categories. As a result of the philosophical and methodological analysis, the initial ideological attitudes and epistemological guidelines of the research object are created.

In interdisciplinary social and humanitarian studies, the epistemological framework of human genome is set by the category of value. It dialectically combines ideas about the benefits of scientific advances in genetics, which allow solving complex social and individual problems and saving the biological uniqueness of a person. This dialectical unity forms the basis of modern bioethics.

During the construction of a subject and formation of programs for interdisciplinary studies of human genome, other fundamental concepts of science, as well as the categorical structure of science in general, also play the methodological role.

General scientific methodological principles play an important role in the determination of the boundaries of an object, the application of which is not limited to one or two sciences. These include both meaningful general scientific concepts that affect all or at least some set of fundamental scientific disciplines simultaneously (idealization, formalization, modeling,) and formal developments and theories associated with the solution of a fairly wide range of methodological problems (game theory, theory systems, methods of cybernetics).

In modern interdisciplinary social and humanitarian studies of human genome, the methodological principles of the systems approach are clearly manifested: the consideration of the variety of forms and methods of interaction of genome with the surrounding reality, as well as the identification of the totality of elements (structure) of human genome.

In research we used simple general scientific methods of analysis, synthesis, comparison, deduction, induction, etc. are used along with complex general scientific methodological principles. For example, during the study of the psychological effects of the reveal of the results of clinical exome and genome sequencing, the psychological results of participants in various clinical conditions were assessed. The method was a meta-analysis of the random effects of anxiety, depressive symptoms and multidimensional exposure. As a result, it was concluded that there was no clinically significant psychological harm from the results of clinical sequencing of exome and genome [22].

A special scientific methodological approach focuses the object on the methodological direction of research within the framework of a particular science. It declares a general research strategy, which is based on a concept or principle. Using a special scientific methodological approach, the object is considered from a certain point of view, normatively set by a specific scientific methodology.

In interdisciplinary social and humanitarian studies of human genome, conducted by legal scientists, a special conceptual and categorical apparatus (legal relationship, offense, legal liability, losses, the regime of legal protection of information, etc.) and legal constructions (models of public relations regulated by law or their elements), which were the means of the formal legal (dogmatic) method of legal science, had a methodological nature. Using these means, based on legal dogma, there is a study of social reality and the specifics of social relations associated with the receipt, storage and use of human genome.

For example, defining human genome as a subject of interdisciplinary research, O.A. Puchkov used the legal structure of the legal relationship, which served as a special legal instrument (method) to determine the object, and then the subject of research i.e. the synthetic theory of genomic legal relationship as a result of the simultaneous application of the method of ascent from the abstract to the concrete and the formal legal method [23].

In interdisciplinary social and humanitarian studies of human genome, empirical data are often obtained using sociological methods. One study, for example, tested the hypothesis about the influence of ethnic identity on beliefs and intentions of people to take into account the results of their genome sequencing. As a research method, a sociological survey method was used to assess social and behavioral structures associated with health, genomics and ethnic identity of the reference group of people who agreed to sequencing.

As a result, it was found that people with stronger ethnic identities (Afro-Caribbean) pay more attention to cognitive beliefs, such as the value of genome results, when considering results, compared to people with weaker ethnic identities [24].

The Delphi method occupies a special place among the group of sociological methods used in interdisciplinary social and humanitarian studies of human genome. The essence of the method is in an anonymous, correspondence and multi-level assessment by a group of experts of upcoming events or the result of any activity.

According to the Delphi method, from May 2015 to December 2016, a three-stage study of the social acceptability of the current and potential future use of non-invasive prenatal testing technology using extracellular DNA (allows identifying the number of genetic risks and conditions in fetus) was carried out, which caused ethical, legal and social problems associated with the infringement of widespread prenatal 
genetic testing on the freedom of decision-making by future parents [25].

The Delphi method provided the empirical evidence which laid the basis for Human Genome Editing Report, published in September 2020, which suggested a translation route for limited approval of germline editing under special circumstances and subject to a set of criteria. The study involved about three dozen experts from the field of genome editing, medicine, bioethics, law and related fields [26].

In order to obtain comprehensive research results, several multilevel methods can be used at once. For example, the GetPreCiSe researchers used several methods to fulfill the knowledge gaps that provoked discussions about genetic privacy and identity, including experimental methods (such as game theory) and ethnographic methods (such as interviews and surveys).

As a result of these studies, it was concluded that (1) despite the fear of losing confidential genetic data, people are still willing to participate in genomic research in order to improve public health; (2) those who do not fully trust biomedical researchers or institutions believe in the value of biomedical research and predominance of benefits to society over risks to personal life; (3) the participation in genomic research is determined by a variety of factors, including previous experience of discrimination, level of education and demographic variables; (4) to maintain trust of vulnerable population, transparent ethical standards with respect to data confidentiality/data exchange, reliable means of protection against data misuse are required [27].

\section{Conclusion}

As a result of this study, the hypothesis of the author about the interdisciplinary interaction of social sciences and humanities in the study of human genome was confirmed. The interest of the representatives of social and humanitarian sciences in the study of human genome is explained by necessary socio-humanitarian intersubject connections, which are determined by the special significance of the consequences of the study and use of human genome for society and each person individually.

In the course of the research, the methodological interaction of natural and social sciences and humanities was revealed, as a result of which such synthetic areas of knowledge as psychogenetics and behavioral genetics occurred.

Human genome is the object of interdisciplinary social and humanitarian research devoted to the social regulation of genomic research and the legal protection of genomic information aimed to eliminate the risks of unlawful use of the results of genomic research. They are aimed to standardize (foresee in this sense) the studies on human genome and the use of their results.

The subject of interdisciplinary social and humanitarian research is the legal nature of human genome; social regulation of research of human genome, in particular, prohibitions and restrictions in work with human genome; methodology of interdisciplinary research of human genome; risks of intentional and accidental leak of genomic information, etc.

The methodology of interdisciplinary social and humanitarian research is represented by methodological means of three levels.

At the level of philosophical and methodological analysis, the epistemological framework of human genome was set by the category of value, which dialectically combined the ideas about the benefits of the studies on human genome and definition of the biological uniqueness of humans.

At the level of general scientific methodological principles in interdisciplinary social and humanitarian studies on human genome, the methodological principles of the system approach were used (consideration of the variety of forms and methods of interaction of genome with the surrounding reality, as well as the identification of the set of elements (structure) of human genome), as well as elementary general scientific methods of analysis, synthesis, comparison, deduction, induction, etc.

The level of a special scientific methodological approach in the interdisciplinary social and humanitarian studies analyzed by the author was represented by a special conceptual and categorical apparatus of legal science and legal constructions that acted as means of the formal legal (dogmatic) method, sociological survey methods, questionnaires and the Delphi method.

The study was carried out at the expense of subsidies from the federal budget for the implementation of a scientific project on the topic: "Determination of the problems of legal regulation in the field of using genetic and genomic information. Preparation of scientifically grounded proposals to amend the system of Russian legislation in order to eliminate them" (topic code: FEUW-2020-0005).

\section{References}

1. K.P. Harden, "Reports of My Death Were Greatly Exaggerated": Behavior Genetics in the Postgenomic Era, Annual Review of Psychology, 72, 37-60 (2021)

2. I.Ya. Kozachenko, D.N. Sergeeva (eds.), Genetic Research: Legislation and Criminal Policy. Collective monograph (SAPIENTIA Laboratory, Yekaterinburg, 2019) p. 48.

3. J.M. Fletcher, Q. Lu, Health policy and genetic endowments: Understanding sources of response to Minimum Legal Drinking Age laws, Health Economics (United Kingdom), 30(1), 194-203 (2021)

4. K. Pormeister, Genetic research and applicable law: the intra-EU conflict of laws as a regulatory challenge to cross-border genetic research, Journal of law and the biosciences, 5(3), 706-723 (2018). https://doi.org/10.1093/jlb/lsy023

5. M.E. Coors, Genetic Research on Addiction: Ethics, the Law, and Public Health, American journal of psychiatry, 170(10), 1215-1216 (2013) 
6. Qingxiu Bu, Reassess the Law and Ethics of Heritable Genome Editing Interventions: Lessons for China and the World, Issues in Law \& Medicine, 34(2), 115-146 (2019)

7. S.H. Katsanis, Pedigrees and perpetrators: Uses of DNA and genealogy in forensic investigations, Annual Review of Genomics and Human Genetics, 21, 535-564 (2020)

8. E. Niemiec, H.C. Howard, Ethical issues related to research on genome editing in human embryos, Computational and structural biotechnology journal, 18, 887-89(2020)

9. N. Doronina, N. Semilyutina, M. Tsirina, Methodology of interdisciplinary research on the example of scientific research of the human genome, E3S Web of Conferences, 215, 05008 (2020)

10. A. Nordberg, T. Minssen, O. Feeney et al., Regulating germline editing in assisted reproductive technology: An EU cross-disciplinary perspective, Bioethics, 34(1), 16-32 (2020)

11. E.V. Luneva, Legal support of environmental safety with targeted and non-targeted changes in the genome of living organisms, Journal of Environmental Treatment Techniques, 7 (Special Issue), 935-938 (2019)

12. A.A. Mokhov, A.N. Levushkin, A.N. Yavorsky, Genome editing of human embryo: Allow or prohibit? Journal of Advanced Research in Law and Economics, 11(2), 483-490 (2020)

13. R. Yotova, Regulating Genome Editing under International Human Rights Law, International and Comparative Law Quarterly, 69(3), 653-684 (2020)

14. N.G. Doronina, N.G. Semilutina, M.A. Tsirina, Bioinformatics and Issues of Conclusion a Contract for Provision of Medical Services, Lecture Notes in Networks and Systems, 160 LNNS, 99-107 (2021)

15. N.M. Kolosova, Modern Model of Genomic and Other Research Regulations, Journal of Siberian Federal University - Humanities and Social Sciences, 13(6), 1020-1027 (2020)

16. Z. He, J. Zhou, Inference attacks on genomic data based on probabilistic graphical models (2020)

17. S.A. Vasiliev, A.K. Burtsev, A.M. Osavelyuk, S.H. Sarmanayev, G.N. Suvorov, Legal regulation of consent to the provision of biomaterial for genome research in the USA, International Journal of Advanced Research in Engineering and Technology, 11(4), 461-467 (2020)

18. Tracking genetic discrimination, Nature Genetics, 52(5), 465 (2020)

19. G. Marchant, M. Barnes, J.P. Evans, B. LeRoy, S.M. Wolf, From Genetics to Genomics: Facing the Liability Implications in Clinical Care, Journal of Law, Medicine and Ethics, 48(1), 11-43 (2020)

20. A.G. Blinov, M.M. Lapunin, E.V. Evstifeeva, O.A. Yakovleva, Foreign Experience of Legal Regulation and Protection of Relations in the Sphere of Genome Editing, Lecture Notes in Networks and Systems, 111, 611-617 (2020)

21. D. Krekora-Zając, Civil liability for damages related to germline and embryo editing against the legal admissibility of gene editing, Palgrave Communications, 6(1), 30 (2020)

22. J.O. Robinson, J. Wynn, B. Biesecker, Psychological outcomes related to exome and genome sequencing result disclosure: a metaanalysis of seven Clinical Sequencing Exploratory Research (CSER) Consortium studies, Genetics In Medicine, 21(12), 2781-2790 (2019)

23. L.N. Berg, Genome, man, law: problems of theory and practice of legal impact (Jurlitinform, Moscow, 2021) $200 \mathrm{p}$.

24. E. Turbitt, M.C. Roberts, B.M. Hollister, Ethnic identity and engagement with genome sequencing research, Genetics In Medicine, 21(8), 1735-1743

25. C. Dupras, S. Birko, A.O. Affdal et al., Governing the futures of non-invasive prenatal testing: An exploration of social acceptability using the Delphi method, Social Science and Medicine, 112930 (2020)

26. M. Angrist, R. Barrangou, F. Baylis, F. Zhang, K. Davies et al., Reactions to the National Academies/Royal Society Report on Heritable Human Genome Editing, CRISPR Journal, 3(5), 332-349 (2020)

27. L. Davis, Stewards of the genome: ethical issues related to data privacy and sharing in psychiatric genetics research, European Neuropsychopharmacology, 2, Attachement 4, 1049 (2018) 